\title{
Análise e aproveitamento da gordura de resíduos de abatedouros de aves
}

\author{
Analysis and use of the fat of residues in \\ slaughterhouses of chickens
}

Olívio Fernandes Galão ${ }^{1}$; Jurandir Pereira Pinto²; Dionísio Borsato ${ }^{1}$

\begin{abstract}
Resumo
Foram realizadas análises de amostras de gordura de frangos de abate. Os produtos da metanólise da gordura por ácido sulfúrico indicaram, por meio de cromatografia gasosa acoplada a espectrofotômetro de massas, a presença de ácidos graxos insaturados e grande quantidade de colesterol. A reação dessa gordura, com uma solução aquosa de hidróxido de sódio, forneceu um sabão de boa qualidade.

Palavras-Chave: Frango de granja, ácidos graxos, colesterol, saponificação, esterificação.
\end{abstract}

\begin{abstract}
Analyses of fat samples of chickens from slaughterhouses were carried out. The products of the methanolysis of the fat in sulfuric acid showed, through coupled gaseous chromatography with mass spectrometer, the presence of unsaturated fat acids and a great amount of cholesterol. The treatment of that fat with caustic soda resulted in a soap of good quality.

Key words: chickens, fat acids, cholesterol, saponification, esterification.
\end{abstract}

\section{Introdução}

A carne de aves é considerada de boa qualidade nutricional pelo seu alto teor protéico, baixo colesterol e baixo teor de ácidos graxos saturados. É um alimento de fácil digestão, sendo indicado na alimentação infantil, de pessoas idosas e convalescentes (MORAES et al., 1987). O Brasil é o segundo maior produtor e exportador mundial de carne de frango, ficando somente abaixo dos Estados Unidos. A produção brasileira de carne de frango atingiu 7,5 milhões de toneladas em 2002 (ASSOCIAÇÃO BRASILEIRA DOS EXPORTADORES DE FRANGOS, 2002). Londrina e região contam com vários abatedouros e os frangos de granja também são criados em várias regiões do estado do Paraná, o que permite que o preço da carne se torne acessível à camadas mais baixas da população. Os resíduos da industrialização do frango são aproveitados por fabricas de ração animal e a gordura, por indústrias de sabão. A determinação da

\footnotetext{
1 Professores do Departamento de Química/CCE da Universidade Estadual de Londrina. Cx.P. 6001, CEP 86051-990, Londrina-PR

${ }^{2}$ Técnico de Nível Superior do Departamento de Química /CCE da Universidade Estadual de Londrina.
} 
composição de ácidos graxos por cromatografia gasosa é uma análise amplamente realizada (ACKMAN, 2002; CARTONI, 2001; COLOMBINI, 2002; NICHOLS; DAVIES, 2002). A transformação dos ácidos graxos em ésteres torna-os mais voláteis, facilitando a sua determinação por cromatografia gasosa. Existem vários métodos para a preparação de ésteres metílicos de ácidos graxos (CARTONI, 2001). O método mais comum consiste em tratá-los com excesso de metanol, usando ácido sulfúrico como catalisador (GONÇALVES; WAL; ALMEIDA, 1988).

Este trabalho teve como objetivo estudar a composição de ácidos graxos da gordura e sua capacidade de saponificação, para obter um sabão de baixo custo, fácil fabricação e útil para limpeza em geral.

\section{Materiais e Métodos}

\section{Obtenção do sabão}

Aproximadamente $1200 \mathrm{~g}$ de cada um dos resíduos, denominados óleo de vísceras puro e óleo de vísceras com pouco sebo, foram aquecidos até $80^{\circ} \mathrm{C}$ em manta de aquecimento, até sua completa fusão. Adicionou-se, a cada uma das porções, $100 \mathrm{~g}$ de hidróxido de sódio dissolvidos em $100 \mathrm{~mL}$ de água, em pequenas porções, sob constante agitação. Após a completa adição de hidróxido de sódio, a mistura foi agitada por 10 minutos, o que proporcionou a formação de uma massa pastosa bastante densa. Essa massa ainda quente foi colocada em forma de plástico para resfriamento e descanso. Após uma hora, a massa de cor marrom escura foi cortada em pedaços ${ }^{3}$. Depois de resfriada ela apresentou consistência dura semelhante à do sabão comercial.

\section{Derivatização dos óleos}

A uma amostra de $10 \mathrm{~g}$ do óleo de vísceras, foram adicionadas $20 \mathrm{~mL}$ de metanol P.A. e 2 gotas de ácido sulfúrico concentrado. A mistura foi aquecida sob refluxo durante 60 minutos, para obtenção de ésteres metílicos de ácidos graxos. Após o resfriamento, separaram-se 2 camadas. $\mathrm{O}$ excesso de metanol foi removido por aquecimento em capela. Após a retirada do metanol, a mistura foi colocada num funil de decantação, no qual houve a separação da parte inferior correspondente aos ésteres metílicos (GONÇALVES; WAL; ALMEIDA, 1988).

\section{Análise dos produtos}

Os produtos obtidos a partir da derivatização foram injetados em cromatógrafo CG/EM (marca Shimadzu modelo QP-5000), tendo como gás de arraste o hélio, na razão de $1 \mathrm{~mL} / \mathrm{min}$. A coluna DB1 da J \& W Scientific GC é constituída de dimetil polisiloxane, de 30 metros, com a espessura do filme de $0,25 \mathrm{~mm}$. A temperatura da coluna foi mantida a $40^{\circ} \mathrm{C}$ durante 4 minutos; em seguida, a temperatura foi elevada na razão de $10^{\circ} \mathrm{C}$ por minuto até $320^{\circ} \mathrm{C}$. A temperatura do injetor foi de $300^{\circ} \mathrm{C}$, e a temperatura do detector $230^{\circ} \mathrm{C}$. A identificação dos ácidos graxos foi feita através de espectrômetro de massa por impacto eletrônico (ACKMAN, 2002; CARTONI et al., 2001; LANÇAS, 1993; NICHOLS; DAVIES, 2002).

\section{Resultados e Discussão}

O cromatograma (Figura 1) apresentou 7 picos, que foram analisados pelo detector de massas. Esses picos, quando comparados à biblioteca NIST62 (National Institute of Standards and Technology, Shimadzu Corporation, Kyoto, Japan), indicaram a presença respectivamente de: éster metílico do ácido hexadecanóico, ácido hexadecanóico, éster metílico do ácido (E,E)-9,12-octadecadienóico, éster metílico do ácido (Z)-9-octadecenóico, um possível isômero do éster metílico do ácido (E,E)-9,12octadecadienóico, ácido oléico e colesterol. 


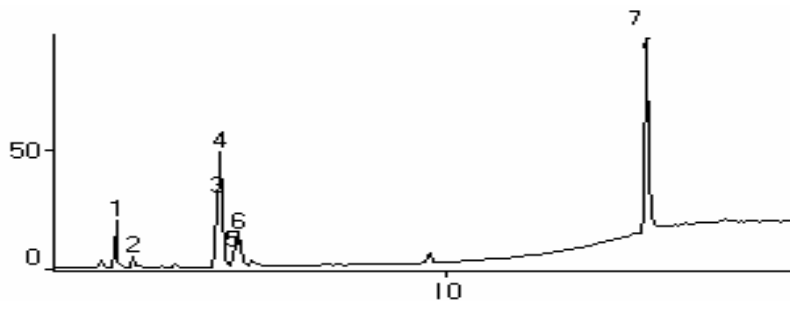

Figura 1 - Cromatograma da gordura de frango de abate, após tratamento com metanol em meio ácido.

Na Tabela 1, são apresentadas as porcentagens dos componentes presentes na amostra de gordura de aves após a derivatização. Os produtos da metanólise da gordura, catalisados por ácido sulfúrico concentrado, indicaram ácidos graxos insaturados e $45 \%$ de colesterol.

Tabela 1 - Composição química da gordura de frangos após a metanólise.

\begin{tabular}{|c|c|c|c|}
\hline Pico ${ }^{\circ}$. & $\begin{array}{c}\text { Retenção } \\
(\min )\end{array}$ & Produto & Porcentagem \\
\hline 1 & 4,97 & $\begin{array}{c}\text { Éster metílico do ácido } \\
\text { hexadecanóico }\end{array}$ & 8.87 \\
\hline 2 & 5,24 & Ácido hexadecanóico & 1.94 \\
\hline 3 & 6,51 & $\begin{array}{c}\text { éster metílico do ácido } \\
\text { (E,E)-9,12- } \\
\text { octadecadienóico }\end{array}$ & 12.34 \\
\hline 4 & 6,58 & $\begin{array}{c}\text { éster metílico do ácido } \\
\text { (Z)-9-octadecenóico }\end{array}$ & 20.93 \\
\hline 5 & 6,78 & $\begin{array}{c}\text { Isômero do éster } \\
\text { metílico do ácido (E,E)- } \\
9,12 \text {-octadecadienóico }\end{array}$ & 5.88 \\
\hline 6 & 6,85 & Ácido oléico & 4.77 \\
\hline 7 & 13,10 & colesterol. & 45.27 \\
\hline
\end{tabular}

Os picos 1 e 2, observados na figura 1, representam, por meio da análise por espectrometria de massas, na amostra original, a mesma substância química visto que, o éster metílico do ácido hexadecanóico foi obtido a partir do ácido hexadecanóico. Portanto, os picos 1 e 2 (Tabela 1) representam a mesma substância perfazendo 10,81\% de ácido hexadecanóico na amostra original.

Os picos 4 e 6, do cromatograma (Fig. 1), por meio da análise por espectrometria de massas, com tempo de retenção bastante distinto, correspondem, de acordo com a biblioteca NIST, ao éster metílico e ácido oléico. Isto indica que apenas uma parte do ácido oléico presente na amostra original sofreu derivatização.

O pico 5 não foi perfeitamente identificado pela biblioteca NIST. Considerando o tempo de retenção muito próximo àquele apresentado para o éster metílico do ácido (E-Z)-9-12-octadecadienóico (Pico 3) pode se tratar de um possível isômero deste éster.

O produto obtido da saponificação da gordura apresentou aspecto consistente, duro, de coloração marrom escura. $\mathrm{O}$ teste de espumabilidade, utilizando solução aquosa a $1 \%$ mostrou que o produto apresenta espuma consistente semelhante a do sabão comercial $^{3}$. A saponificação foi rápida durando apenas 15 minutos. O sabão obtido apresentou uma boa performance no teste de espuma

\section{Conclusões}

Os rejeitos dos abatedouros de frangos, ricos em gordura, podem ser aproveitados para a produção de sabão. O processo de saponificação é rápido e o produto obtido apresentou aspecto consistente. $\mathrm{O}$ sabão não apresentou bom aspecto para comercialização, mas possui boa capacidade de limpeza e formação de espuma.

O estudo da gordura por cromatografia gasosa, após derivatização dos ácidos presentes, indicou a presença predominante de ácidos graxos insaturados, e $45,27 \%$ da parte injetada no cromatógrafo correspondiam a colesterol. $\mathrm{O}$ alto teor de colesterol (VANDEBOVENKAMP; KATAN， 1981; GONÇALVES, 1988) apresentado não recomenda o uso dessa gordura na alimentação humana ou animal, podendo ser empregado na indústria saboeira. A presença de alguns ácidos graxos livres, mostra que o processo de esterificação não foi completo. 


\section{Referências}

ACKMAN, R. G.; The gas chromatograph in pratical analysis of common and uncommon fatty acids for the $21^{\text {st }}$ century. Analytica Chimica Acta, n. 465, p.175 192, 2002.

\section{ASSOCIAÇÃO BRASILEIRA DOS}

EXPORTADORES DE FRANGOS. Produção, exportação e consumo interno. Disponível em: <www.abef.com.br>. Acesso em: out. 2002.

BORSATO, D.; MOREIRA, I.; GALÃO, O. F. Detergentes naturais e sintéticos, um guia técnico. Londrina: Ed. UEL, 1999.

VANDEBOVENKAMP, P.; KATAN, M. T. Cholesterol Content of chicken skin. Journal of Food Science, v.46, n.1, p.291-292, 1981.

CARTONI, G. et al. Characterisation of fatty acids in drying oils used in paintings on canvas by GC and GCMS analysis. Annali di Chimica, v.91, n.11-12, p.719726, Nov./Dec. 2001.
COLOMBINI, M. P. et al. A GC-MS study on the deterioration of lipidic paint binders. Michrochemical Journal, Artigo aceito, 2002. No prelo.

FERREIRA, J. M. et al. Efeito de tipo de óleo adicionado à dieta sobre o teor de colesterol em partes da carcaça de frangos de corte de acordo com o sexo e linhagem. Ciência e Tecnologia de Alimentos, Campinas, v.19, n.2, p.189-193, maio/ago.1999.

GONÇALVES, D.; WAL, E.; ALMEIDA R. R.

Química Orgânica Experimental. São Paulo: McGrawHill, 1988.

LANÇAS M. L. Cromatografia em fase gasosa. São Carlos: Ed. ACTA, 1993.

MORAES, M.C.S. et al. Estudo comparativo da gordura de capote, galinha caipira e frango-de-granja. Bol. SBCTA, Campinas, v.21, n.1, p.15-24, jan./mar. 1987.

NICHOLS, D.; DAVIES, N. Improved detection of polyunsatured fatty acids as phenacyl esteres using liquid chromatography-ion trap mass spectrometry. Journal of Microbiological Methods, v.50, n.2, p.103113, July 2002. 